\title{
Services for the Newly Dependent: An Assessment
}

\author{
Edward J. Mullen \\ Community Service Society and \\ Fordham University \\ Robert M. Chazin \\ Fordham University \\ David M. Feldstein \\ Smith College School for Social Work
}

\begin{abstract}
One hundred families who, for the first time, were dependent on public assistance received financial and supportive assistance from the public welfare department and professional social casework services from a family agency. The objective was to demonstrate the effectiveness of this collaborative approach in preventing individual and family disorganization. The effects of these services were evaluated after fourteen months. Differences between the two groups of families, for the most part, were not statistically significant following receipt of service.
\end{abstract}

The number of people receiving public assistance in the United States rose from an estimated 6.2 million persons in 1950 to 14.4 million in February 1971-two decades of unparalleled economic growth. It was in this climate that the Community Service Society of New York (CSS) and the City Department of Social Services (DSS) in November 1966 undertook a service demonstration to test an approach to helping newly dependent public assistance families. This article reports the results of that demonstration.

This effort began with the assumption that many families receiving public assistance for the first time were in need not only of financial help but also of skilled individualized counseling. It was assumed that many of these families would be applying for public assistance because of serious personal and social problems in

This project was funded by the Commonwealth Fund, the Mellon Foundation, the Doris Duke Foundation, interested individuals, and the Community Service Society. The program component was administered by the CSS Department of Family Services and the New York City Department of Social Services (5). 
addition to their economic situations. That is, families would be seeking help following crises such as death, marital dissolution, job loss, and so forth. In such situations it was proposed that skilled individualized counseling would help families cope with their feelings and changed situations and, over time, would facilitate their adjustment. It was expected that many of these families would need help finding and using community resources, such as low-cost health services, housing, employment, and job-training programs. Unless individualized professional casework was made available in addition to financial assistance, it was thought that many of these families would be unable to deal effectively with these problems. Some critics of the public welfare system suggested that the absence of professional counseling services was contributing to the rapidly growing public welfare rolls. They held that the situations leading to a family's need for public assistance were not usually dealt with by the current welfare system, with the result that many families that could otherwise return to independent functioning remained chronically on public assistance. The effects of this chronic dependency and absence of needed services were viewed as detrimental both to society and to the individuals involved. In line with this view, it was held that professional social caseworkers were especially equipped, through their dual skills in personal counseling and environmental intervention, to provide needed services.

\section{Study Design}

Each of the four Family Service Centers of the CSS was paired with a DSS center in the same general geographic area. Each pair of centers offered, in collaboration, combined services to approximately twenty-five families for nearly fourteen months. Families applying to DSS for the first time were randomly assigned to the demonstration group or to a control group. Families in the demonstration group received both CSS and DSS assistance, while families in the control group received only the latter. The effects of this demonstration were evaluated through an independent research plan developed and administered by the CSS Department of Research and Evaluation. ${ }^{1}$ The evaluation used an after-test, singlecontrol-group experimental design. ${ }^{2}$ The data used to evaluate the effects of the demonstration were collected primarily through a structured home interview with the female head of household at the end of the project.

The sample. Referrals to CSS began in November 1966 and were completed by December 1967. Of the 364 referrals made by DSS,

1. Formerly the Institute of Welfare Research.

2. Families were assessed only at the conclusion of the project and not before receipt of service. 
200 met all project criteria. One hundred and eighteen were assigned to the demonstration and 82 to the control group. Of the 118 families assigned to the demonstration group, 97 were seen by a CSS caseworker, and 88 of these had research interviews. Sixty-eight of the 82 control families were seen in research interviews. ${ }^{3}$

Service. The control families received the usual DSS services, which consisted of financial and medical assistance and the casework service of a public assistance worker, who was required to have a bachelor's degree. The demonstration service consisted of the usual assistance provided by DSS, in addition to professional casework counseling provided each family by a CSS caseworker, who held the master's degree in social work. DSS and CSS caseworkers were to coordinate their services on behalf of the families.

In view of the anticipated high caseloads and rapid turnover rate, it was believed that control families would generally not receive the consistent, skilled, and individualized counseling envisioned for the demonstration group. ${ }^{4}$ Initially the plan was that each demonstration family would be assigned to and remain with one of three caseworkers in each of the four CSS Family Service Centers. This was possible for 70 of the 97 families. During the course of the project, 22 CSS caseworkers worked with the families.

While no limit was placed on the number of months of service, each family was to be evaluated approximately fourteen months after the first face-to-face contact with a CSS worker. The number of face-to-face CSS worker interviews ranged from a minimum of one to a maximum of 129 , with a median of $15 .{ }^{5}$ The number of worker-family contacts by telephone and letter ranged from none to a maximum of 81 , with a median of 9.5 contacts per family. Few contacts occurred with collaterals unaffiliated with an organization. CSS worker contacts with other organizations (exclusive of DSS) occurred in all but about 20 percent of the families, although in the majority these contacts were limited to no more than three. In about one-third of the families, there were no face-to-face meetings between the family's CSS worker and its DSS worker. In half the cases in which such meetings did occur, the number of contacts was limited to less than four. In 72.2 percent of the families there were between one and ten telephone and letter contacts between CSS and

3. The research interview completion rate was 87 percent. In all but five cases, the failure to obtain research interviews stemmed from inability to locate families rather than from their refusal. The five families refusing to be interviewed were all in the demonstration group.

4. The identity of the control families was to be known only to the researchers and DSS administration. DSS workers were not to be informed which families were in the control group.

5. Twenty-one of the 118 demonstration families are not included because they were not seen by the CSS worker. 
DSS. Since these contacts spanned thirteen months in half of the families, the data attest to an absence of extensive CSS-DSS collaboration.

Research interview. The primary source of outcome information was a research interview conducted by an interviewer from the CSS Department of Research and Evaluation in the home of each demonstration and control family. ${ }^{6}$ Because it was assumed that any identification of the research interviewer with CSS might affect the responses of the families, respondents were not informed of the CSS affiliation. An interview request letter was sent to each family from the director of the DSS Center from which the family had last received public assistance. The letter requested an interview at a specific time. It explained that DSS was interested in improving its services and that a private organization was conducting interviews with clients to get information that would assist in this process. Families were assured that the information would be confidential and would be reported to DSS in group form only. The research interviewer, who continued to use this explanation when he visited the family, was at no time to identify himself with CSS or to raise questions about CSS. Conducting the interviews under the auspices of DSS may have had an effect on responses; however, it was assumed that this effect would be similar for both the experimental and the control groups. This plan seemed more desirable than use of the CSS affiliation, which might have introduced unknown differential effects. To standardize the information further, the research interview was to be conducted with the female head of the household. It was expected that each family would have a female head, who would be the primary person seen by the CSS caseworker. Although this approach limited the extent of the information obtained, the amount of control gained was assumed to outweigh this limitation.

The content of the interview was based on the objectives of the project, which were presented in general terms, such as improvement in economic, health, employment, and housing conditions of the families. It was assumed that information pertinent to each of these areas could be obtained through direct self-reports and would not require more sophisticated measurement procedures, such as the use of in-depth interviews, objective tests, professional judges, or data from sources other than the families themselves. The research interview, therefore, consisted of the administration of a highly structured, primarily precoded questionnaire with fixedalternative and short-answer questions.

6. Two male research interviewers, both graduate students in social work and both with previous interview experience with low-income families, conducted nearly all the interviews. These interviewers were not told which of the families were in the demonstration group. A double-blind approach was used. 
Because project objectives were stated globally rather than in specific terms, the research questionnaire was developed to obtain information on all areas that, at the time, could be expected reasonably to be dealt with in the collaborative program. For each family information was sought in eleven general areas: economic status, employment, socioeconomic status, use of health facilities, housing condition and practices, marketing and consumer practices, cohesion and relationships, mother's functioning as a parent, psychosocial functioning of children, psychological functioning and status of female family head, and helpfulness of collaborative service.

Questions solicited information on individual and family conditions, behavior, attitudes, and feelings at the point of the research interview. In addition, information was sought on the client's own assessment of change in these areas since the family's application for public assistance. If change was reported, interviewers probed for information about the respondent's view of the cause of that change. Through this latter technique, information on the recognized effects of the collaborative service was obtained. ${ }^{7}$

Hypotheses were developed for each of the eleven general areas of functioning and for indicators within each area. It was not anticipated that all these hypotheses would be supported; however, if differences between the groups did occur, these hypotheses stated the expected direction of the differences.

\section{Characteristics of the Families}

The female family head was the person interviewed and the central figure in most of the families; hence her characteristics were of primary interest in the evaluation. Seventy-six percent of the female family heads were under thirty-six years old; nearly three out of five had not completed high school; approximately 56 percent were black, 27 percent white, 15 percent Puerto Rican, and 12 percent of Chinese or non-Puerto Rican Caribbean origin; 57 percent had been residents of New York City eleven years or more; 66 percent had been born outside of the city; four out of every five were members of families with fewer than six members; and 66 percent were not living with their spouses.

7. The questionnaire was composed largely of items thought to have face validity. In addition, six scales were used. The marketing scale and the child-rearing scale developed by Joan Gordon were included as measures of the female family head's marketing practices and child-rearing attitudes (4). Four subscales of the Parental Attitude Research Inventory were also included to measure dimensions of the female family head's parenting attitudes. These four dimensions were selected on the basis of Geismar's report that they discriminated among lower socioeconomic families (3:563-70). The draft questionnaire was refined after its use in a pretest with twenty-six nonproject CSS families. 
Heads of families differed somewhat from the general public assistance population in New York City at the time in that they were usually younger, more of ten Protestant, better educated, less often Puerto Rican, more often white; they somewhat more frequently were living with their spouses; they had a shorter New York City residency; and, if migrants to the city, they had come at an older age than is typical of the public assistance population. ${ }^{8}$ These differences may be largely explained by the eligibility criteria for this project.

Reasons for seeking public assistance varied. The largest proportion of the families had sought assistance because the male wageearner had left because of divorce, desertion, or separation, had died, or was institutionalized. Discontinuance of support payments or of assistance from relatives or friends was another frequent reason for application. In other instances a family member was working and supplemental assistance was needed. About one out of every four families required assistance because the wage-earner had lost his job by being laid off or discharged. About the same number needed assistance because the wage-earner had become ill or disabled. In most of these families the female family head was unable to work because she was needed for child care. ${ }^{9}$

\section{Outcomes}

Eighty-three items were examined, seventy-one dealing with family functioning and twelve with help received from organizations or professional workers. Only one of the seventy-one items on family functioning indicated a significant difference between the demonstration and the control groups. That was one of nine items designed to reflect a family's attempt to improve its housing situation. During the period of the project 24 percent of the demonstration families, but only 11.8 percent of the control families, reported that a family member had complained to an authority other than the landlord or his agent about the condition of the apartment or building in which the family lived. ${ }^{10}$

It was assumed that help from the demonstration service would be reflected in the twelve items in the "Helpfulness of Collaborative Service" area. Three of the twelve "help received" questions resulted in statistically significant differences. More demonstration than

8. Figures for the New York City population, provided by the New York City Department of Social Services in April 1970, reflected the caseload in December 1965.

9. In the absence of significant differences between the demonstration and control groups on these sample characteristics, we concluded that they were similar at the inception of the project. The level of significance used as the criterion throughout this project was .05 , although differences at the .10 level are reported.

10. $\chi^{2}=3.35$, d.f. $=1, \mathrm{p}<.05$, one-tailed. 
control families reported having received organizational or professional help in getting medical services ( 26 percent versus 10.6 percent).${ }^{11}$ The other two significant differences were items reflecting the CSS service itself. More families in the demonstration group reported having received organizational or professional help with personal or family difficulties (62.9 percent versus 23.5 percent) $)^{12}$ and a larger number of appointments concerned with personal or family difficulty. ${ }^{13}$

In only these four items out of the 83 were statistically significant differences found. Three additional contrasts resulted in differences that, while not statistically significant at the .05 level, were significant at the more lenient .10 probability level. Specifically, more demonstration than control families were no longer receiving welfare (27.6 percent versus 16.2 percent) ${ }^{14}$ had completed or were involved in job training (17.3 percent versus 8.8 percent) $),{ }^{15}$ and reported organizational or professional help with getting an apartment (14.6 percent versus 0.0 percent). ${ }^{16}$

When those demonstration-group families that had no in-person contact with the CSS caseworker were eliminated from the comparisons ${ }^{17}$ and the 83 contrasts were recomputed, two additional differences favoring the demonstration families were found. Significantly more families reported having received organizational or professional help with getting an apartment ${ }^{18}$ and with marketing and budgeting information. ${ }^{19}$

Finally, only those families that had had at least five in-person interviews with the CSS worker were contrasted with the control families on the 83 comparisons. One additional difference reached statistical significance. More demonstration families reported having received helpful advice, information, or counseling from a professional worker concerning their marital situation. ${ }^{20}$ When all these results are combined, we find that six of the twelve "Helpfulness of Collaborative Service" items and three of the seventy-one items in the nine areas of family functioning reached significance at the more lenient .10 probability level.

Additional analyses. The relationship between the number of

11. $\chi^{2}=5.03$, d.f. $=1, p<.02$, one-tailed.

12. $\chi^{2}=24.05$, d.f. $=1, p<.001$, one-tailed.

13. $t=5.28$, d.f. $=171, \mathrm{p}<.001$, one-tailed.

14. $\chi^{2}=2.43$, d.f. $=1, \mathrm{p}<.10$, one-tailed.

15. $\chi^{2}=1.81$, d.f. $=1, \mathrm{p}<.10$, one-tailed.

16. $\chi^{2}=2.58$, d.f. $=1, \mathrm{p}<.10$, one-tailed.

17. Families assigned to the demonstration group who for a number of reasons did not subsequently have interviews with the CSS caseworker were retained in the previously reported analysis to ensure the demonstration group's comparability with the control group.

18. $\chi^{2}=4.60$, d.f. $=1, p<.05$, one-tailed.

19. $\chi^{2}=4.14$, d.f. $=1, p<.05$, one-tailed.

20. $\chi^{2}=5.41$, d.f. $=1, \mathrm{p}<.02$, one-tailed. 
months a family was active with CSS and whether it was on public assistance at the termination of the project was also examined. The longer a family remained on public assistance, the more likely it was to continue receiving CSS service. Such a finding suggests that service of this type in itself will not result in making families independent of public assistance. ${ }^{21}$

Additional questions were: Did families in the control group receive other professional counseling? If so, did elimination of these families change the results of the demonstration-control-group contrasts? On the basis of a very liberal definition of counseling, eighteen of the control families were found to have received such service. When these families were eliminated, the control-group scores were higher than before. We concluded that the general lack of strong demonstration-control-group differences could not be attributed to the fact that some families in the control group had received counseling services.

Another question of interest was: Were education, family structure, and ethnicity associated with outcome and, if so, are there differences in the functioning of the demonstration and control groups when these influences are controlled? Education and ethnicity of the female family head were found to be highly associated with outcome and, to a lesser extent, family structure (one-parent and two-parent families) was also associated with outcome. ${ }^{22}$ However, differences between the demonstration and control groups generally did not occur when these characteristics were held constant. The only exception was that demonstration-group white and Puerto Rican respondents reported more improvement than their controlgroup counterparts in three component items of the scale measuring the psychological functioning of the female family head.

One of the objectives of this demonstration was to help families, when feasible and desirable, to move toward self-support. Because the evaluation indicated that the demonstration had not achieved this goal to a major extent, an attempt was made to specify those family characteristics that were associated with a family's continuance on welfare. Three were identified as significantly associated with continued receipt of public assistance: ethnicity, education, and marital status. In all, 55.6 percent of the white respondents, compared to 76.6 percent of the black and 84.6 percent of the Puerto Rican, were receiving public assistance at the time of the research interviews. Similarly, 54.3 percent of the married female family heads, compared to 85.9 percent of the unmarried, ${ }^{23}$ were receiving

21. This finding is open to a variety of interpretations. Causality cannot be implied.

22. More favorable outcomes tended to be found among the more highly educated, the white, and the two-parent families.

23. Separated, divorced, never married. 
assistance. Finally, 93.3 percent of the respondents with less than a ninth-grade education were still receiving assistance, compared to only 73.4 percent of those having completed ninth grade but not high school, and only 60.4 percent of those with the high-school diploma. ${ }^{24}$ Differences between the demonstration and control groups on receipt of public assistance were not evident when these three characteristics were controlled. ${ }^{25}$

Summary. These various analyses provide only modest evidence in support of the study hypotheses. Considering the large number of contrasts examined and the limited number of significant differences found, one is compelled to draw the conclusion that, although the demonstration families did report having received help, the program did not produce the expected benefits. This evaluation further specifies the importance of an individual's educational level, ethnicity, and family structure in understanding his public assistance status and general functioning.

\section{Discussion}

Problems in evaluative research. This evaluation illustrates two critical problems confronting the researcher evaluating the effectiveness of social interventions: the limited development of practice theory and the limitations of evaluative research methodology.

As pointed out by Vinter (11:123-24), practice theory tends to govern the type of research conducted. The current fragmented theoretical base of social work practice severely limits the evaluator in his attempts to identify appropriate outcome variables for assessment. Ideally, the helping professions would have explicated what might be called a series of "problem-intervention-outcome" typologies that would specify in unambiguous terms the types of problems each attempts to prevent or ameliorate, the specific nature of the interventions used for each of the problems, and the expected effects of each of the interventions. Such typologies would serve as a guide to the evaluator by pointing clearly to the nature of the particular program goal to be assessed. Needless to say, such an idealized state is far from realized. In its absence the evaluator must

24. All these differences were statistically significant.

25. Since ethnicity, education, and marital status of the female family head were found to be associated with public assistance status at the time of the research interview, our expectation was that they were interrelated to a significant degree and their separate relationships with public assistance status would be an artifact of that common feature. We found no relationship between the female family head's marital status and educational level or ethnicity. The female family head's ethnicity and her educational level, however, were found to be significantly related. The black as well as the white woman tended to have more education than the Puerto Ricans. 
in most studies settle for a far less precise and somewhat more arbitrary set of outcome variables. Evaluations of the effectiveness of the helping professions have coped with this difficulty with varying degrees of success.

Wayne Vasey noted in his evaluation of the Chemung County study:

It must be acknowledged that placing the burden of definition [in casework evaluations] on the instrument or measurement, a not uncommon practice, is the price paid by the profession for its lack of clearly specified treatment objectives. By this lack the profession leaves itself vulnerable [10:35].

Equally important is the need for a methodologically appropriate design. This brings us face-to-face with the limited development of evaluative research, as practiced in the applied social sciences. While a considerable amount has been written about the designs and methods of evaluation, it was not until recently (the past fifteen years) that field experiments utilizing experimental designs have been conducted to any notable extent in the social work profession (see Mullen and Dumpson [6]). Therefore, like practice theory, evaluative research as applied to social interventions is still in a phase that requires substantial development.

Interpretation of findings. The study findings, which reflect but modest differences between the experimental and control families, cannot readily be explained by any single factor. Rather, these findings are reflective of a number of interrelated influences.

The absence of preliminary knowledge about the characteristics of the population this project attempted to serve may go a long way in explaining the failure to demonstrate the effectiveness of the services delivered. Services based on limited knowledge of the target population are bound to be less potent than services based on more extensive knowledge. Very little is known about individuals and families receiving welfare, and even less about new welfare families. An analyst and planner within the Department of Health, Education, and Welfare, in reviewing a Task Force Report dealing with this problem, wrote: "Although periodic surveys revealed some characteristics of the total welfare population, there were no data that would indicate what new welfare families were like, where they came from, or how they differed from families already on the rolls" (9:19). Practitioners and agencies dealing with families on public assistance know much about the characteristics of the individual families with whom they are dealing. However, what is frequently not known is how similar these particular families are to the larger population of concern. Interventions planned on the basis of selective experiences may not be effective or appropriate when applied to larger populations.

A major factor that may have influenced the results of this 
evaluation was the limited collaboration between CSS and DSS. By plan, CSS and DSS were to work closely with each family for its general welfare. As pointed out above, in about one-third of the families the CSS workers reported an absence of any face-to-face contacts with DSS staff. The median number of such CSS-DSS contacts per family was only two, with a maximum of eight reported for any one family. CSS-DSS worker contact through the telephone or letters was also limited, with the median number of seven per family. In a strict sense, then, the collaborative program as planned was not implemented. The complex reasons for this failure attest to the importance of not underestimating the difficulties involved in large-scale collaborative ventures between public and private welfare agencies.

It was assumed that many families applying for public assistance for the first time experience a crisis in their lives leading to need for assistance. As an example, it was thought that some families would come for assistance as a result of death in the family, illness, marital breakup, and so forth. It was also assumed that for some families the reality of being economically dependent on public assistance would constitute a crisis. It was expected that these families would be critically in need of immediate assistance and receptive to assistance during the crisis period. The data do not clarify whether or not these families actually were in a crisis state at the time of their application for public assistance. Many experienced precipitating events that could have led to a crisis. However, whether or not a crisis reaction was to any extent prevalent remains speculative. It may be that the findings are partially explained by the fact that there were few crisis situations. The amount of time lapsing between application for public assistance and actual engagement of families at CSS-usually more than a month-raises further questions about the workers' opportunities to help families during the period of crisis. Whatever crisis a family did experience before its application for public assistance may well have abated by the time the CSS worker saw the family. The absence of more extensive service effects may have stemmed partially from agency inability to intervene with families at the point of crisis.

An additional explanation of the limited effectiveness of the services given may be the nature of the problems confronting these families. According to the CSS caseworkers, the four problems most often confronting these families, in order of frequency, pertained to finance, marital relationships, employment, and housing. Three of these (finance, employment, and housing) are what might be considered environmental or social problems. From a systems perspective they involve not only the individual and family systems but also the neighborhood, the community, and, indeed, the urban systems. To the extent that systems beyond the individual and his family are 
involved in these problems, intervention focused for the most part on the individual and his family and not structured to deal with these surrounding conditions may be expected to have limited effects. Given the nature of these problems, the limited capacity of the families served in this study, and the limited opportunity in New York City, one may question how feasible change was for many of these families.

It has been assumed by some critics that many environmental problems are associated with the families' lack of knowledge about resources, as well as their limited skill is using resources. It has been suggested that by providing information and making appropriate referrals the caseworker can help these families solve their problems. To the extent that the problems of these families resulted from inadequate information and skill in using community resources, it might be expected that assistance of the kind offered in this project would be helpful. However, to the extent that these problems were reflective of difficulties in systems beyond the family and the absence of opportunity in the environment for these families, one would anticipate a lack of service effectiveness in relation to these problems (8). ${ }^{26}$

An additional factor to be considered in an attempt to explain the lack of major differences between the groups is the matter of services received by the control families. In a strict sense this study did not have a "control group," but a "contrast group." These families received the normal services of DSS. In view of the nature of the problems confronting these clients it may well be that the DSS service and assistance had an impact on these families similar to that resulting from the combined CSS-DSS service. Many families in the demonstration as well as the control group reported that they had received help of various kinds from their DSS workers. In addition, many families reported having received help from friends, from various nonprofessional community residents, and from other community agencies. Given the nature of many of the practical problems confronting these families, perhaps help with practical matters rendered by these sources was a critical input. Evidence from some recent studies supports the view that less highly trained workers, as well as indigenous and nonprofessional helpers, are in some instances as effective with problem-solving as are professional workers (2). It may be that the assistance provided these families by the combined CSS-DSS intervention was effective, but not to an extent significantly different from that resulting from DSS services

26. In a previous survey of female family heads receiving public assistance it was found that the women knew of many available services. In that study the more frequently required medical and dental services were known to about 95 percent of the sample (8:9-10 and passim). 
alone or that provided through the community of which these clients were a part.

A final explanation for the limited success found in this study relates to the impact of the amount of financial support provided these families. This project implicitly assumed that collaborative service could have a measurable impact on the social functioning of families within the existing limitation on the amount of financial assistance provided by DSS. It may be that a more adequate income than was provided at the time of the study is a necessary condition for professional casework service to be most effective. ${ }^{27}$

Implications. The contribution conventional individualized counseling can make as society attempts to alleviate the problems of poverty is currently under debate (1). That role is in the process of being reformulated within the context of a new society marked by changing values and knowledge, as well as by increased complexity and social concern. Previous definitions of "poverty" and "welfare" are being rethought and reformulated. In this context a major task at hand for the social work community is to participate in this process and to identify and communicate what it is that social workers can and cannot be expected to do that will affect the social condition of poverty and the individuals involved. As it grapples with this task, the profession should seriously consider the growing number of evaluations of its programs and act on their implications.

The evaluation reported in this article, when considered along with other assessments of social work programs with poverty families, raises a serious question. Can individualized counseling services of the conventional casework type bring about environmental changes that significantly modify the problem of poverty when such services are offered in isolation from a larger intervention program? If one were to define poverty as a social condition resulting from the inadequate performance of individuals, and further view this poor performance as susceptible to change via personal influence, then the implication to be drawn from this and similar studies might be that what is needed is more effective counseling services. On the other hand, if one views poverty as a condition emanating from the way society operates, as an expression of a certain type of social structure, then the implications to be drawn from these assessments might point to development of qualitatively different types of interventions, such as those based on a systems perspective.

This study has again drawn attention to the individual suffering and deprivation associated with poverty and the need of resources for those in poverty. It has once again illustrated the fact that

27. The findings of a recent Baltimore study support this view and illustrate the impact of an increased grant in combination with skilled service (7). 
personal counseling alone does not fulfill that need. We expect that skilled individualized social assistance can be most useful to those in poverty when that assistance is supported by the provision of adequate financial and material resources and is offered as part of a multilevel intervention addressed to relevant components of the community system, of which the poverty group is a part. We further expect that if it is to have the desired impact on the lives of individuals in poverty the social work profession will need to emphasize skills in socioenvironmental services, community development, and social policy formulation.

Received August 17, 1971

\section{References}

1. "Any End to Poverty." U.S. News and World Report, July 12, 1971, pp. 52-57.

2. Carkhuff, Robert R. Helping and Human Relations: A Primer for Lay and Professional Helpers. Vols. 1 and 2. New York: Holt, Rinehart \& Winston, 1969.

3. Geismar, Ludwig, and Krisberg, Jane. "The Family Life Improvement Project: An Experiment in Preventive Intervention, Part I." Social Casework 47 (November 1966): 563-70.

4. Gordon, Joan. The Poor of Harlem: Social Functioning in the Underclass. New York: Office of the Mayor, Interdepartmental Neighborhood Service Center, 1965.

5. Mullen, Edward J.; Chazin, Robert M.; and Feldstein, David M. Preventing Chronic Dependency. New York: Community Service Society of New York, 1970.

6. Mullen, Edward J., and Dumpson, James R., eds. The Effects of Social Intervention: Implications of Program Evaluations. San Francisco: Jossey-Bass, 1972. In preparation.

7. Olson, Irene. "Some Effects of Increased Aid in Money and Social Services to Families Getting AFDC Grants." Child Welfare 44, No. 2 (February 1970): 94-100.

8. Pomeroy, Richard. Studies in Public Welfare: Reactions of Welfare Clients to Social Service. New York: Center for the Study of Urban Problems, City University of New York, 1968.

9. Rivlin, Alice M. Systematic Thinking for Social Action. H. Rowan Gaither Lectures, January 1970, Berkeley, California. Washington, D.C.: Brookings Institution, 1971.

10. Vasey, Wayne. "Implications for Social Work Education." In The Multi-Problem Dilemma: A Social Research Demonstration with Multi-Problem Families, edited by Gordon E. Brown, pp. 32-46. Metuchen, N.J.: Scarecrow Press, 1968.

11. Vinter, Robert D. "Small-Group Theory and Research: Implications for Group Work Practice Theory and Research." In Social Science Theory and Social Work Research, edited by Leonard S. Kogan, pp. 123-34. New York: National Association of Social Workers, 1960. 